\title{
Public opinion on community-based education and exercise programs for managing hip and knee osteoarthritis-like symptoms: results of a survey
}

This article was published in the following Dove Press journal:

Patient Preference and Adherence

9 March 2016

Number of times this article has been viewed

\author{
Aileen M Davis ${ }^{1-5}$ \\ Marvilyn Palaganas \\ Linda C Li ${ }^{6,7}$ \\ 'Division of Health Care and \\ Outcomes Research, ${ }^{2}$ Arthritis \\ Community Research and \\ Evaluation Unit, Krembil Research \\ Institute, University Health \\ Network, ${ }^{3}$ Department of Physical \\ Therapy, Institute of Health Policy, \\ ${ }^{4}$ Management and Evaluation, ${ }^{5}$ Institute \\ of Rehabilitation Science, University \\ of Toronto, Toronto, ON, ${ }^{6}$ Arthritis \\ Research Canada, Richmond, \\ ${ }^{7}$ Department of Physical Therapy, \\ University of British Columbia, \\ Vancouver, BC, Canada
}

Introduction: In North America, delivery of targeted exercise and education programs by health professionals for people with hip and knee osteoarthritis (OA) poses challenges related to cost and access. Linking the wellness and health sectors could increase program availability. We evaluated if people with OA were willing to participate in programs delivered by trainers in community centers/gyms.

Methods: We conducted an online survey of the general public in Canada over a period of 2 months. Participants included those aged $\geq 30$ years with self-reported chronic OA-like knee or hip pain. We evaluated access to community/fitness centers, exercise frequency, interest in attending an evidence-based program twice a week for 6 weeks, and willingness to pay. Analyses included descriptive statistics with $95 \%$ confidence intervals and chi-square tests to evaluate factors associated with willingness to attend the program.

Results: After removing duplicate records, 751 respondents completed the survey with 408 likely having hip and/or knee OA and never having received a joint replacement. These 408 respondents had an age range of 30 to $\geq 75$ years and $86 \%$ were female. Of the $408,(63.7 \%)$ were between 45 and 64 years of age. Only two respondents reported that a community center was $>1$ hour away. One hundred and fifty-six (38\%) reported a current membership, and 203 (50.4\%) reported exercise 3 days/wk, $120(29.8 \%)<3$ days, and $80(19.9 \%)$ reported no exercise. Two hundred and ninetyseven respondents $(73.7 \%$ ) were willing to attend a program, and, of these, $26 \%$ were willing to pay $\$ 100$ Cdn or more. Age, sex, access to a community center/gym, current gym membership, and current frequency of exercise were not significantly associated with willingness to attend a program.

Conclusion: Almost $75 \%$ of respondents with OA, despite one in three having a community center membership, were interested in attending a targeted program delivered in community/ fitness centers. A program in the wellness sector may be a viable option to support people in managing their hip and or knee OA.

Keywords: osteoarthritis self-management, neuromuscular exercise, community gyms, internet survey

\section{Introduction}

Osteoarthritis (OA) of the hip and knee is common in the developed world. For example, OA affects one in six adult Canadians. ${ }^{1}$ Based on the US data, the estimated lifetime risk of knee OA alone is $45 \%$ by 85 years. $^{2}$ Two of three people are under 65 years ${ }^{3}$ with $10 \%$ reporting symptomatic knee OA by 60 years of age. ${ }^{4}$ Poorly managed hip and knee OA results in severe chronic pain, limited mobility, and disability ${ }^{5-11}$ and is associated with cardiovascular disease, diabetes, and obesity. ${ }^{12,13}$ High health care usage, total joint replacement, ${ }^{14-16}$ and increased mortality ${ }^{12,13}$ are hallmarks of poorly
Correspondence: Aileen M Davis Division of Health Care and Outcomes Research, Krembil Research Institute, MPI I-322, 399 Bathurst Street, Toronto, ON M5T 2S8, Canada

Tel +l 4166035543

Fax + I 4166036288

Email adavis@uhnresearch.ca 
managed OA. Given the current and rising prevalence of hip and knee OA, ${ }^{1}$ strategies to improve care and limit the sequelae of $\mathrm{OA}$ are critical.

Current treatment guidelines for the management of mild-to-moderate hip and knee OA recommend exercise, weight management, and pain medication as first-line treatment to manage and limit symptoms, structural damage, and disability. ${ }^{17,18}$ Self-management, incorporating these guidelines, and patient education related to $\mathrm{OA}$ are the mainstay of managing early-to-moderate symptoms and disability. ${ }^{17,18}$ Some countries, eg, Sweden, ${ }^{19}$ Demark, ${ }^{20-22}$ and Australia, ${ }^{23}$ have implemented programs nationally to support self-management in people with hip and knee OA. These programs are delivered by health professionals, often working in multidisciplinary teams. Program participants pay a nominal fee (eg, Sweden and Denmark), whereas some programs are supported by the national health system (eg, Australia). Current evidence indicates that these structured programs can improve an individual's symptoms, function, and quality of life; ${ }^{19-22}$ however, it is unclear if these programs are directly transferrable across jurisdictions due to differences in health care models and funding structures.

Delivery of such programs by health professionals, such as physiotherapists (PT), poses significant challenges in Canada, largely related to access and cost. ${ }^{24}$ While Canada has a universal health care coverage, paid services include only access to a primary care physician and inpatient hospital services. Any additional services are determined by the individual provinces/territories. For example, Medicare provides coverage for some programs such as the classes provided at the Mary Pack Arthritis Program, ${ }^{25}$ and the Ontario Division of the Arthritis Society ${ }^{26}$ provides evaluation and management strategies for people with arthritis. However, the vast majority of community-based PT services for OA are not covered under provincial health care plans except following surgery or in special populations. Most individuals must have third-party coverage or pay out of pocket. Hence, even if referred for PT, many people do not seek care. Furthermore, many primary care physicians report that they do not refer to PT as their patients are unable to pay. ${ }^{24}$ This challenge is not unique to Canada as many health care systems/provider agencies do not provide or provide only limited coverage for rehabilitation services.

In order to address the burden of OA and increase access to evidence-based, targeted programs for people with hip and knee OA, we need to consider alternative solutions. Trainers in community gyms, local parks and recreation programs, and for-profit fitness centers present a potentially viable alternative. While individuals with more complex problems require care from a health care professional, many with mild-to-moderate symptoms could be supported in selfmanagement outside the health sector. To our knowledge, programs such as those offered in Sweden and Denmark for people with OA have not been adapted for delivery beyond the health care sector.

A recent meta-analysis found that supervised exercise programs were most effective. ${ }^{27}$ Trainers in the wellness sector are educated to provide exercise in the context of asymptomatic joints, and they have expertise in motivating individuals to exercise. Trainer education is variable but completion of a university or community college-based program (eg, kinesiology, exercise physiology or fitness, and health promotion) is common. Additionally, wellness/ fitness facilities require that trainers complete in-house educational programs for certification to work in the facility. However, the literature shows that a critical component of a successful program in the context of health conditions is that participants perceive the individuals delivering the program as skilled and knowledgeable. ${ }^{28}$ Trainers, therefore, require additional education related to OA pathology, protective joint positioning and neuromuscular (NM) performance in the face of pain, and joint pathology, to be well placed to deliver programs.

Although there is a fee to access programs in the wellness sector, programs delivered by certified trainers are a less expensive option than health professionals, as many fitness facilities and community recreation centers allow nonmembers to access classes/programs for a nominal fee. These fees are much less than per visit fees for private physiotherapy. Hence, linking the wellness and health sectors provides an opportunity to increase the availability of programs for people with OA.

There is some precedent with provision of services to people with health conditions in the health and wellness sector (eg, following stroke or total hip or knee replacement ${ }^{29}$ and osteoporosis). ${ }^{30}$ However, many of these programs are designed for those aged $\geq 60$ years (eg, OsteoFit). To our knowledge, no specific programs exist in the wellness sector for people with mild-to-moderate signs and symptoms of hip or knee OA, particularly for younger individuals. ${ }^{31}$

Prior to implementing such programs, there is a need to determine whether people would be willing to participate in such programs. We describe the results of a public survey designed to elicit people's interest in participating in an evidence-based, targeted program for people with hip and knee OA provided by trainers in community fitness and recreation facilities. 


\section{Methods}

During September and October 2014, we conducted a cross-sectional online survey to elicit people's willingness to participate in a community-based education and exercise program delivered by trainers, similar to the national program provided in Denmark by PTs. In Denmark, PTs are educated by the program developers over 2 days to deliver the program. This OA program for people with hip and or knee OA consists of two education sessions plus a 6-week, twice weekly targeted NM exercise program that has been shown to be effective in improving pain and function. ${ }^{20-22}$ The groupbased NM program includes ${ }^{32}$ a four-station circuit: 1) core stability/postural function, 2) postural orientation, 3) lower extremity muscle strength, and 4) functional exercises. Each station includes two exercises with three progressive levels of difficulty performed in two to three sets having 10-15 repetitions with individual dose and level determined based on NM functioning and pain.

Eligible participants for the survey were members of the general public in Canada, aged $\geq 30$ years, and experiencing chronic hip or knee OA-like pain, who had not had a prior hip or knee replacement surgery. Invitations were distributed by the Arthritis Research Canada (mainly a British-Columbiabased research center) and Arthritis Consumer Experts (a nationwide patient education organization) through their social media channels (Facebook and Twitter), emails, online newsletters, and word of mouth. The survey was administered using LimeSurvey with the data stored at Arthritis Research Canada. The study was approved by the research ethics board of the University of British Columbia. Participant consent was implied based on the completion of the survey.

The online survey, developed by Davis and Li, was designed to be completed in $<5$ minutes and included 15 questions. In the first section, we collected demographic data. In the second section, we determined eligibility, that is, confirmed or likely hip and or knee OA based on a "yes" response to any of the following questions: a health professional diagnosis of OA; ever having been told you have OA or "wear and tear" in your joints and/or the definition commonly used in population surveys, ${ }^{33}$ specifically pain, aching, or discomfort in or around one or both knees on most days of the past 3 months; pain, aching, or discomfort in or around one or both hips on most days of the past 3 months; pain, aching, or discomfort in or around your shoulders, hands, neck, and back on most days in the past 3 months. We also asked respondents to indicate if they had a hip or knee replacement surgery. The third and final section asked if the respondent had a gym membership at a community or fitness center and frequency of exercise at a gym or home. Finally, modeled on the Danish program components and length, we asked if respondents would be interested in attending a program led by trainers and if they would be willing to pay for such a 6-week program. Amount willing to pay was based on Canadian dollar values at the time of the survey (ie, September 2014).

\section{Analysis}

Descriptive statistics (proportions or means with 95\% confidence intervals) were calculated for all variables. For those who reported hip/knee OA or symptoms likely to be OA but no joint replacement surgery, we conducted the analysis for the total group, those reporting having symptoms in the hip only ( $\mathrm{n}=77)$, knee only ( $\mathrm{n}=199)$, and both hip and knee $(n=132)$. We evaluated factors that might be associated with interest in attending the targeted OA program (no/yes) irrespective of affected joint using the chi-square test or Fisher's exact test. These factors included age, sex, access to a community center/gym, current gym membership, and current frequency of exercise. $P$-values of 0.05 were considered statistically significant for univariable analyses. Factors significant at $P<0.20$ in univariable analyses were further evaluated using multivariable logistic regression. All analyses were conducted using SAS Version 9.4.

\section{Results}

A total of 899 respondents logged on to the survey and 778 completed the questionnaire. Of those who did not complete the survey, $>75 \%$ did not provide any demographic data. On review of the Internet protocol (IP) addresses and variable-by-variable data for those who completed the survey, 27 records were duplicate, leaving 751 unique records.

Of these 751 respondents, 363 (51\%) reported knee pain and 247 (34\%) reported hip pain. Pain in other joints was reported by 482 (65\%) respondents; $57 \%$ (423) reported that they had been told they had arthritis, and $374(51 \%)$ of the 751 reported that they had been told they have OA. Hip or knee replacement surgery was reported by $73(10 \%)$.

Given our interest in whether people with hip or knee OA or OA-like symptoms would be interested in attending a program delivered by trainers in a community gym or fitness center, all further analyses were conducted in the subsample who reported hip or knee pain, irrespective of whether they had been told they had arthritis or OA by a health professional, who had not had joint replacement surgery. This subsample included 408 respondents. Figure 1 provides a flow diagram of respondents. 
899 participants logged into survey

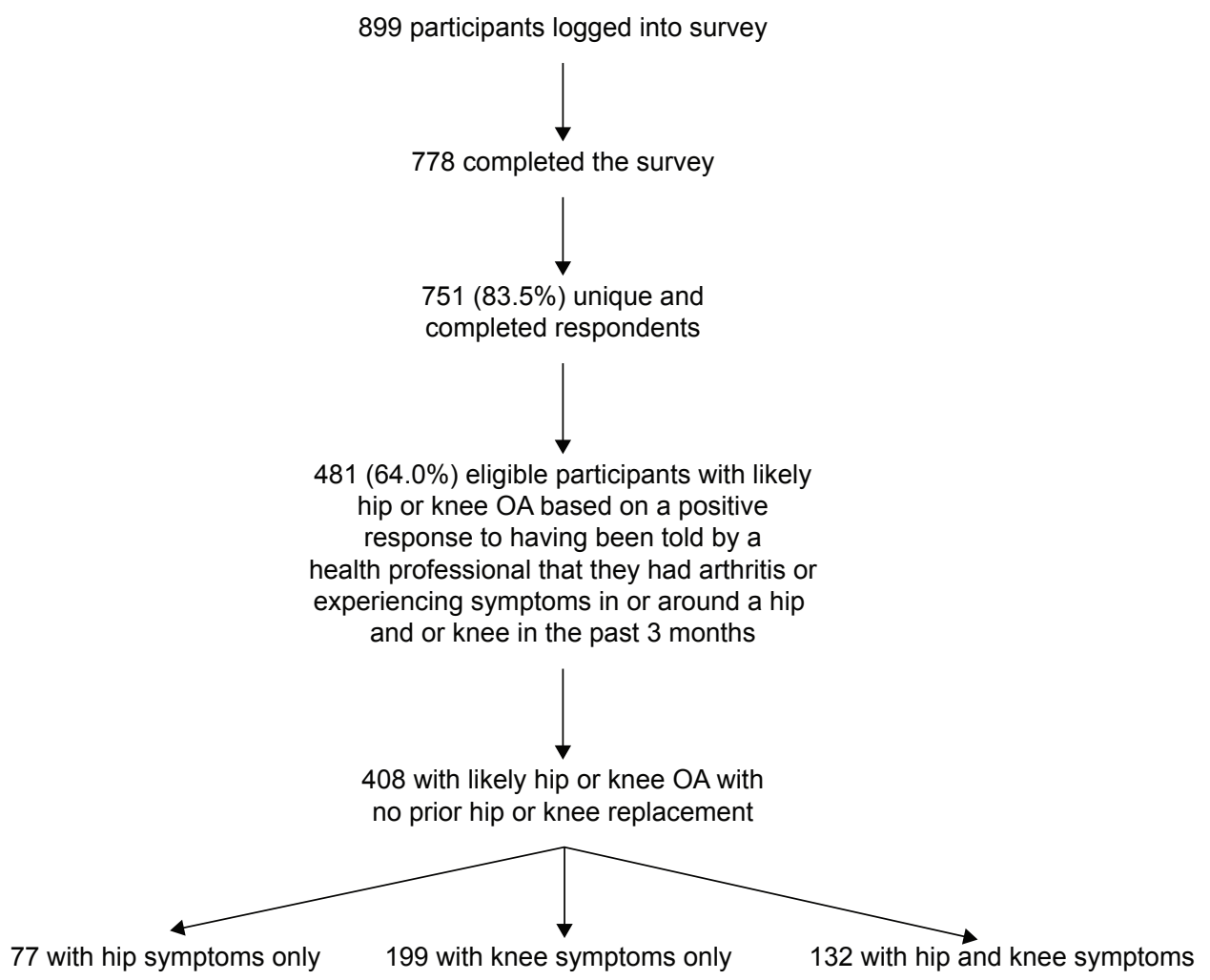

Figure I Flow diagram of respondents and final analytic sample.

Abbreviation: $\mathrm{OA}$, osteoarthritis.

The geographic location of this subsample $(n=408)$ included $77 \%$ from British Columbia, 12\% from Ontario, and 5\% from Quebec, with the remaining sample from other provinces. Table 1 provides descriptive information for the sample overall $(\mathrm{n}=408)$. Table $\mathrm{S} 1$ provides the detailed descriptive data for the subgroups reporting hip OA symptoms only ( $\mathrm{n}=77)$, knee OA symptoms only (199), and both hip and knee OA symptoms $(n=132)$.

The majority of the 408 respondents (63.7\%) reporting hip and/or knee OA were between 45 years and 64 years of age and $86.5 \%$ (353) were female. All but four respondents $(1 \%)$ indicated that there was a community center or gym within 1 hour of their residence. Gym memberships were relatively common $(38.4 \%)$. Twenty percent $(n=80)$ of respondents indicated that they never exercised; $29.8 \%$ $(n=120)$ indicated they exercised less than three times per week; and 50.4\% $(n=203)$ exercised at least 3 days/wk. Even though many were already exercising, 297 (73.7\%) indicated that they were interested in attending a 6-week, twice per week, targeted education and exercise program to improve their knee and or hip symptoms. Of the 297 who indicated interest in attending a program, 238 responded to the willingness to pay question. Overall, participants indicated they were willing to pay a nominal amount with $\sim 74 \%$ indicating they would pay $\$ 100$ or less and $26 \%$ willing to pay $\$ 100$ Cdn to $\$ 250$ Cdn (2014).

Willingness to attend the 6-week program (no/yes) was not associated with age, sex, place of residence, proximity to a gym, or frequency of exercise ( $P>0.05$ for all comparisons) in univariable analyses (Table 1). However, age and frequency of exercise had $P$-values of $<0.20$ (Table 1) and were evaluated with multivariable logistic regression. Neither variable was statistically significantly associated with willingness to attend nor was an interaction of age by frequency of exercise statistically significant.

\section{Discussion}

There is an urgent need to provide evidence-based education and exercise programs for the growing number of adults with hip and knee OA to assist them in managing their condition. Approaches to delivery of such programs need to consider alternatives beyond the expensive health care system to increase availability and improve access. The results of this survey indicate that the majority of the 408 respondents with hip and knee symptoms commensurate with OA were interested in attending an education and targeted exercise program in an attempt to manage their symptoms. Specifically, they were willing to attend such a program delivered by trainers in 
Table I Summary of participant description and willingness to participate in community-based programs by trainers ( $\mathrm{n}=408$ )

\begin{tabular}{|c|c|c|c|}
\hline & n (\%) & $\begin{array}{l}95 \% \text { confidence } \\
\text { interval for proportion }\end{array}$ & $\begin{array}{l}\text { Association with willingness } \\
\text { to attend (no/yes) ( } P \text {-value) }\end{array}$ \\
\hline Age (years) (n=408) & & & 0.06 \\
\hline $30-34$ & $30(7.3)$ & $4.8,9.8$ & \\
\hline $35-44$ & $49(12.0)$ & $8.8,15.2$ & \\
\hline $45-54$ & $109(26.7)$ & $22.4,31.0$ & \\
\hline $55-64$ & I5I (37.0) & $32.3,41.7$ & \\
\hline $65-74$ & $59(14.5)$ & II.I, 17.9 & \\
\hline$\geq 75$ & $10(2.4)$ & $0.9,3.9$ & \\
\hline $\operatorname{Sex}(n=408)$ & & & $0.40^{\mathrm{a}}$ \\
\hline Female & $353(86.5)$ & $83.2,89.8$ & \\
\hline Male & $55(13.5)$ & $9.3,15.7$ & \\
\hline Gym facilities in community $(n=406)$ & & & $0.59^{b}$ \\
\hline Many gym facilities & $321(79.0)$ & $75.0,82.9$ & \\
\hline I or 2 gyms & $66(16.3)$ & $12.7,19.9$ & \\
\hline Gym not nearby but within I-hour drive & $15(3.7)$ & $0.02,0.06$ & \\
\hline No gym or $>$ I-hour drive & $4(1.0)$ & $0.0,0.02$ & \\
\hline Gym membership ( $n=406)$ & & & $0.25^{\mathrm{a}}$ \\
\hline Yes & $156(38.4)$ & $33.7,43.1$ & \\
\hline No & $250(6 \mid .6)$ & $56.9,66.3$ & \\
\hline Exercise frequency $(n=403)$ & & & 0.10 \\
\hline 3 or more days/wk & $203(50.4)$ & $45.5,55.2$ & \\
\hline$<3$ days & $120(29.8)$ & $25.4,34.2$ & \\
\hline No exercise & $80(19.9)$ & $16.0,23.8$ & \\
\hline $\begin{array}{l}\text { Willingness to attend a program in } \\
\text { a community center or gym }(n=403)\end{array}$ & & & - \\
\hline Yes & $297(73.7)$ & $69.4,78.0$ & \\
\hline No & $106(26.3)$ & $22.0,30.6$ & \\
\hline Amount willing to pay $\left(n=238^{c}\right)$ & & & - \\
\hline$<\$ 50$ & $89(37.4)$ & $31.2,43.5$ & \\
\hline$\$ 50-\$ 100$ & $87(36.5)$ & $30.4,42.6$ & \\
\hline$\$ 100-\$ 150$ & $38(16.0)$ & II.3, 20.7 & \\
\hline$\$ 150-\$ 200$ & $14(5.9)$ & $2.9,8.9$ & \\
\hline$\$ 200-\$ 250$ & $10(4.2)$ & $1.6,6.7$ & \\
\hline
\end{tabular}

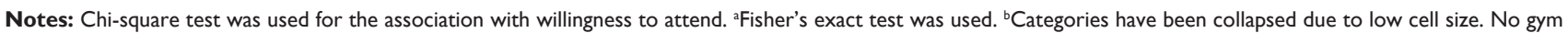
nearby but within I-hour drive and no gym or $>$ I-hour drive were combined to one category. 'Based on those willing to attend a program who responded to the willingness to pay question in 2014 Canadian dollars (238 of 297).

the wellness sector (ie, community centers/fitness facilities) in an attempt to manage their symptoms. This is despite many respondents reporting that they already exercise quite regularly. Additionally, among those who were interested in attending such a program, the vast majority indicated that they were willing to pay a modest fee.

Our findings need to be considered in the context of specifically asking about interest in and willingness to attend a program specifically delivered by trainers in the wellness sector and current provision of OA care. Traditionally, OA is diagnosed and managed in primary care with prescription of medication for symptom control and guidance for selfmanagement by the health care team, often the primary care physician, sometimes including referral to physiotherapy. However, gaps exist in exercise prescription. For example, a survey of 1,713 people with knee/hip OA found that only
$25 \%$ of people with no contraindication to exercise were given exercise advice. ${ }^{34}$ Additionally, as previously noted, primary care physicians often do not refer patients to physiotherapy due to inability to pay. ${ }^{24}$ Developing programs to support OA self-management that include education and targeted exercise within the wellness sector partnered with the health care sector provides an opportunity to address this gap by increasing program availability and access in communities. Partnership and trust will be critical in developing implementation and evaluation strategies of such programs. Health professionals as well as people with OA need to have confidence that the program is evidence based and that the trainers providing the program are appropriately educated and trained to deliver the program.

The majority of our respondents with hip and knee OA symptoms $(83 \%)$ were between 30 years and 64 years of 
age and the relatively high proportion of people already exercising (just over one in three) were still interested in a targeted program. Some recent literature supports these results. In a qualitative study of people aged 30-65 years with knee OA symptoms recruited from the community, MacKay et al found that people were looking to manage their symptoms, wanting to limit progression, and avoid or a least delay the need for joint replacement. ${ }^{35}$ MacKay et al also reported that people with mild-to-moderate knee symptoms were struggling for guidance to find effective methods to manage their symptoms. ${ }^{35}$ Respondents in that study reported that they used trial and error and found little guidance from their medical team. Additionally, despite evidence-based guidelines that recommend exercise as a first-line treatment for $\mathrm{OA},{ }^{17,18}$ the survey by $\mathrm{Li}$ et al described earlier found that people with OA were rarely given exercise advice. ${ }^{34}$ Overall, these findings seem to support the need for programs for people looking to manage their hip and knee OA.

Community-based programs will likely incur some costs to participants given the context of the Canadian health care system. Approximately one-third of respondents indicated that they would be willing to pay a modest amount for a program delivered in the wellness sector. Costs for programing will vary across community centers but in some cases, programs, such as those for people post hip or knee replacement, are included as part of the facility membership. ${ }^{29}$ In other cases, short-term memberships (eg, 3 months) or programonly fees can be paid ${ }^{37}$ which will limit costs. Some of these centers also have supported fee programs to limit barriers to access for those in need. ${ }^{19}$ Costs for physiotherapy also are variable in Canada such that it is difficult to determine a cost per visit. For example, the Physiotherapy Association of British Columbia indicates that the fee for a private PT visit ranges from $\$ 63 \mathrm{Cdn}$ to $\$ 190 \mathrm{Cdn} .{ }^{38}$ Future comparative studies will be important in determining if delivery of programs in the wellness sector is cost-effective. ${ }^{29,36}$

We also attempted to identify factors that might be associated with willingness to attend a program delivered by trainers in the wellness sector, including age, sex, province, proximity to a gym, and frequency of exercise hoping to gain an understanding of factors that might influence attendance. However, none of these factors were statistically significantly associated with willingness to attend a program.

This study has several limitations. The results of this study need to be considered within the challenges of Internetbased public opinion surveys generally. ${ }^{38}$ Achieving sampling coverage within the target population is challenging as those without Internet are excluded and it is impossible to disentangle access issues, lack of awareness of the survey, and choosing not to respond. Access to the Internet in Canada was high (83\%) and growing in 2012, and $48 \%$ of those $\geq 65$ years of age reported using the Internet for personal use. While we anticipate there was likely higher access during our survey in 2014, we have no way of knowing if fewer people aged $\geq 65$ years had a lower response rate due to limited access or if they simply chose not to answer the survey. ${ }^{39}$ The majority of our sample was from one province, also limiting generalizability of the results, and we do not know if our sample included a mix of urban and rural respondents. Although this survey was not restricted to members of organizations that distributed the survey invitation, our participants might have different characteristics compared with a population-based sample. Hence, our findings should be viewed with caution.

Finally, while we used screening questions used in population-based surveys to identify whether people likely had $\mathrm{OA},{ }^{33}$ we cannot be sure that respondents truly had a diagnosis of hip or knee OA.

\section{Conclusion}

In conclusion, supervised education and exercise programs are effective in controlling and limiting progression of symptoms and functional limitations in people with hip and knee OA. ${ }^{17,18,27}$ However, provision of effective programs is limited in many jurisdictions. There is a need to consider methods of delivery which avoid the costly health care system for this highly prevalent condition. The results of this survey indicate that targeted education and exercise programs developed for and delivered in community centers/fitness facilities by trainers educated to deliver programs may be a viable option to increase available programs and services for people with mild-to-moderate knee and or hip OA. Future research will be required to evaluate the cost-effectiveness of such programs.

\section{Disclosure}

The authors report no conflicts of interest in this work.

\section{References}

1. Public Health Agency of Canada [webpage on the Internet]. Life with Arthritis in Canada: A Personal and Public Health Challenge. 2010. Available from: http://www.phac-aspc.gc.ca/cd-mc/arthritisarthrite/lwaic-vaaac-10/pdf/arthritis-2010-eng.pdf. Accessed March 2, 2014.

2. Murphy L, Schwartz TA, Helmick CG, et al. Lifetime risk of symptomatic knee osteoarthritis. Arthritis Rheum. 2008;59:1207-1213.

3. Centre for Disease Prevention and Control. Prevalence of doctordiagnosed arthritis and arthritis-attributable activity limitation-United States, 2010-2012. MMWR Morb Mortal Wkly Rep. 2013;62:869-873. 
4. Losina E, Weinstein AM, Reichmann WM, et al. Lifetime risk and age at diagnosis of symptomatic knee osteoarthritis in the US. Arthritis Care Res. 2013;65:703-711.

5. Jinks C, Jordan K, Croft P. Measuring the population impact of knee pain and disability with the Western Ontario and McMaster Universities Osteoarthritis Index (WOMAC). Pain. 2002;100(1-2):55-64.

6. Grotle M, Hagen KB, Natvig B, Dahl FA, Kvien TK. Prevalence and burden of osteoarthritis: results from a population survey in Norway. J Rheumatol. 2008;35:677-684.

7. Peat G, McCarney R, Croft P. Knee pain and osteoarthritis in older adults: a review of community burden and current use of primary health care. Ann Rheum Dis. 2001;60:91-97.

8. Murray CJL, Lopez AD. The Global Burden of Disease: A Comprehensive Assessment of the Mortality and Disability from Diseases, Injuries and Risk Factors in 1990 and Projected to 2020. Boston, MA: Harvard School of Public Health on behalf of the World Health Organization and the World Bank; 1996.

9. Felson DT, Zhang Y. An update on the epidemiology of knee and hip osteoarthritis with a view to prevention. Arthritis Rheum. 1998; 41:1343-1355.

10. Sadosky AB, Bushmakin AG, Cappelleri JC, Lionberger DR. Relationship between patient-reported disease severity in osteoarthritis and self-reported pain, function and work productivity. Arthritis Res Ther. 2010;12:R162.

11. Hermans J, Koopmanschap MA, Bierma-Zeinstra SM, et al. Productivity costs and medical costs among working patients with knee osteoarthritis. Arthritis Care Res. 2012;64:853-861.

12. Nuesch E, Dieppe P, Reichenbach S, Williams S, Iff S, Juni P. All cause and disease specific mortality in patients with knee or hip osteoarthritis: population based cohort study. BMJ. 2011;342:d1165.

13. Hawker GA, Croxford R, Bierman AS, et al. All-cause mortality and serious cardiovascular events in people with hip and knee osteoarthritis: a population based cohort study. PLoS One. 2014;9:e91286.

14. Bombardier C, Hawker G, Mosher D [webpage on the Internet]. The Impact of Arthritis in Canada: Today and Over the Next 30 Years. Toronto, ON: Arthritis Alliance of Canada; 2011. Available from: http://boneandjointcanada.com/wp-content/uploads/2014/05/BJC-OAMeeting-Report-Final.pdf. Accessed November 15, 2015.

15. Kotlarz H, Gunnarsson CL, Fang H, Rizzo JA. Insurer and out-of-pocket costs of osteoarthritis in the US: evidence from national survey data Arthritis Rheum. 2009;60:3546-3553.

16. Le TK, Montejano LB, Cao Z, Zhao Y, Ang D. Healthcare costs associated with osteoarthritis in US patients. Pain Pract. 2012;12:633-640.

17. Fernandes L, Hagen KB, Bijlsma JW, et al; European League Against Rheumatism (EULAR). EULAR recommendations for the nonpharmacological core management of hip and knee osteoarthritis. Ann Rheum Dis. 2013;72:1125-1135.

18. McAlindon TE, Bannuru RR, Sullivan MC, et al. OARSI guidelines for the non-surgical management of knee osteoarthritis. Osteoarthritis Cartilage. 2014;22:363-388.

19. Thorstensson CA, Garellick G, Rystedt H, Dahlberg LE. Better management of patients with osteoarthritis: development and nationwide implementation of an evidence-based supported osteoarthritis selfmanagement programme. Musculoskeletal Care. 2015;13:67-75.

20. Skou ST, Odgaard A, Rasmussen J, Roos EM. Group education and exercise is feasible in knee and hip osteoarthritis. Dan Med J. 2012; 59:A4554.

21. Skou ST, Simonsen ME, Odgaard A, Roos EM. Predictors of long-term effect from education and exercise in knee and hip pain in clinical practice. Dan Med J. 2014;61:A4867.

22. Roos EM [webpage on the Internet]. English Summary GLA:D Annual Report 2014. Available from: https:/www.glaid.dk/pdf/English $\% 20$ Summary\%20annual\%20report\%202014\%20GLAD.pdf. Accessed November 16, 2015.
23. New South Wales Agency for Innovation [webpage on the Internet]. Osteoarthritis Chronic Care Program Model of Care. Available from: http://www.aci.health.nsw.gov.au/models-of-care/musculoskeletal/ osteoarthritis-chronic-care-program. Accessed November 16, 2015.

24. Cott CA, Devitt R, Falter LB, Soever L, Passalent L. Barriers to rehabilitation in primary health care in Ontario: funding and wait lists for physical therapy services. Physiother Can. 2007;59:173-183.

25. Vancouver Coastal Health [webpage on the Internet]. Mary Pack Arthritis Program. 2016. Available from: http://www.vch.ca/locations-andservices/find-health-services/?program_id=2654. Accessed November $16,2016$.

26. The Arthritis Society [webpage on the Internet]. Ontario Division of the Arthritis Society Therapy Services. Available from: http://arthritis. ca/manage-arthritis/living-well-with-arthritis/living-well-in-yourprovince/living-well-in-ontario/therapy-services. Accessed November $16,2015$.

27. Juhl C, Christensen R, Roos EM, Zhang W, Lund H. Impact of exercise type and dose on pain and disability in knee osteoarthritis: a systematic review and meta-regression analysis of randomized controlled trials. Arthritis Rheum. 2014;66:622-636.

28. Desmeules F, Toiopoulos P, Roy J-S, et al. Validation of an advanced practice physiotherapy model of care in an orthopaedic outpatient clinic. BMC Musculoskelet Disord. 2013;14:162.

29. YMCA of Hamilton, Burlington, Brantford Programs [webpage on the Internet]. Available from: http://ymcahbb.ca/Locations/Hamilton/ Neighbourhood-One/Les-Chater-Family-YMCA/Programs?category $1=1089 \&$ category $2=1108 \&$ category $3=0 \&$ categoryid=1108. Accessed November 16, 2015

30. OsteoFit [webpage on the Internet]. City of Toronto Parks, Forest and Recreation. Available from: http://www1.toronto.ca/wps/portal/ contentonly?vgnextoid=7fc0dada600f0410VgnVCM10000071d60f89 RCRD\&vgnextfmt=default. Accessed March 23, 2014.

31. Davis AM, Badley EM, McGlasson R, Alleyne J [webpage on the Internet]. Reducing the Impact of OA: A Report on the Prevention and Effective Management in Canada Phase 1: Stakeholder Engagement Phase 2: Meeting. Bone and Joint Canada. Available from: http:// www.arthritisalliance.ca/images/PDF/eng/Initiatives/20111022_2200_ impact_of_arthritis.pdf. Accessed September 2, 2014.

32. Ageberg E, Link A, Roos EM. Feasibility of neuromuscular training in patients with severe hip or knee OA: the individualized goalbased NEMEX-TJR training program. BMC Musculoskelet Disord. 2010;11:126.

33. Centre for Disease Prevention and Control. QuickStats: percentage of adults reporting joint pain and stiffness - a national health interview survey United States 2006. MMWR. 2013;57:467.

34. Li LC, Sayre EC, Kopec JA, Esdaile JM, Bar S, Cibere J. Quality of nonpharmacological care in the community for people with knee and hip osteoarthritis. J Rheumatol. 2011;38:2230-2237.

35. MacKay C, Badley EM, Jaglal SB, Sale J, Davis AM. "We're all looking for solutions": a qualitative study of the management of knee symptoms. Arthritis Care Res. 2014;66:1033-1040.

36. Abilities Centre [webpage on the Internet]. Whitby Abilities Centre Membership. Available from: http://www.abilitiescentre.org/ membership. Accessed November 16, 2015.

37. Physiotherapy Association of British Columbia [webpage on the Internet]. Access, Fees, and Coverage. Available from: http://bcphysio. org/faq/access-fees-and-coverage-physiotherapy-bc. Accessed November 16, 2015.

38. Couper MP. Web surveys a review of issues and approaches. Public Opin Q. 2000;64:464-494.

39. Statistics Canada [webpage on the Internet]. Individual Internet Use and e-Commerce 2012. Available from: http://www.statcan.gc.ca/ daily-quotidien/131028/dq131028a-eng.htm. Accessed December 29, 2015. 


\section{Supplementary material}

Table SI Participant description and willingness to participate in community-based program by trainers

\begin{tabular}{|c|c|c|c|}
\hline & \multicolumn{3}{|c|}{ n (\%; $95 \% \mathrm{Cl}$ for proportion) } \\
\hline & $\begin{array}{l}\text { Hip OA/symptoms } \\
(n=77)\end{array}$ & $\begin{array}{l}\text { Knee OA/symptoms } \\
(n=199)\end{array}$ & $\begin{array}{l}\text { Both hip and knee } \\
\text { OA/symptoms } \\
(n=132)\end{array}$ \\
\hline \multicolumn{4}{|l|}{ Age (years) } \\
\hline $30-34$ & $8(10.4 ; 3.4,17.4)$ & $17(8.5 ; 4.6,12.5)$ & $5(3.8 ; 0.5,7.1)$ \\
\hline $35-44$ & $10(13.0 ; 5.3,20.7)$ & $25(12.6 ; 7.9,17.2)$ & $14(10.6 ; 5.3,15.9)$ \\
\hline $45-54$ & $21(27.3 ; 17.1,37.4)$ & $56(28.1 ; 21.8,34.4)$ & $32(24.2 ; 16.8,31.6)$ \\
\hline $55-64$ & $24(31.2 ; 20.6,41.7)$ & $70(35.2 ; 28.5,41.9)$ & $57(43.2 ; 34.6,51.7)$ \\
\hline $65-74$ & II $(14.2 ; 6.3,22.3)$ & $27(\mid 3.6 ; 8.8,18.4)$ & $21(15.9 ; 9.6,22.2)$ \\
\hline 75 or more & I $(3.9 ; 0.0,8.3)$ & $4(2.0 ; 0.0,4.0)$ & $3(2.3 ; 0.0,4.8)$ \\
\hline \multicolumn{4}{|l|}{ Sex } \\
\hline Female & $66(85.7 ; 77.7,93.7)$ & I7I (85.9; 8I.0, 90.8) & II $6(87.9 ; 82.2,93.5)$ \\
\hline Male & II $(14.2 ; 7.7,24.5)$ & $28(14.1 ; 9.7,19.9)$ & $16(12.2 ; 7.3,19.2)$ \\
\hline \multicolumn{4}{|l|}{ Gym facilities in community } \\
\hline Many gym facilities & $66(86.8 ; 79.1,94.6)$ & $156(78.4 ; 72.6,84.1)$ & $99(75.6 ; 68.1,83.0)$ \\
\hline I or 2 gyms & $9(11.8 ; 4.4,19.3)$ & $32(16.1 ; 10.9,21.2)$ & $25(19.1 ; 12.3,25.9)$ \\
\hline $\begin{array}{l}\text { Gym not nearby but within I hour } \\
\text { drive }\end{array}$ & I $(1.3 ; 0.0,3.9)$ & $9(4.5 ; 1.6,7.4)$ & $5(3.8 ; 0.5,7.1)$ \\
\hline $\begin{array}{l}\text { No gym or more than I hour's } \\
\text { drive }\end{array}$ & 0 & $2(1.0 ; 0.0,0.04)$ & $2(1.5 ; 0.0,0.1)$ \\
\hline \multicolumn{4}{|l|}{ Gym membership } \\
\hline Yes & $26(34.2 ; 23.3,45.1)$ & $76(38.4 ; 31.5,45.2)$ & $54(40.9 ; 32.4,49.4)$ \\
\hline No & $5 \mathrm{I}(66.2 ; 54.4,76.4)$ & $121(60.8 ; 53.6,67.6)$ & $78(59.1 ; 50.2,67.5)$ \\
\hline \multicolumn{4}{|l|}{ Exercise frequency } \\
\hline$\geq 3$ days/week & $45(59.2 ; 47.9,70.5)$ & $96(48.5 ; 41.5,55.5)$ & $62(48.1 ; 39.3,56.8)$ \\
\hline$<3$ days/week & $22(28.9 ; 18.5,39.4)$ & $58(29.3 ; 22.9,35.7)$ & $40(31.0 ; 22.9,39.1)$ \\
\hline No exercise & $9(11.8 ; 4.4,19.3)$ & $44(22.2 ; 16.4,28.1)$ & $27(20.9 ; 13.8,28.0)$ \\
\hline \multicolumn{4}{|c|}{ Willingness to attend a program in a community center or gym } \\
\hline Yes & $54(71.0 ; 60.6,81.5)$ & $143(73.3 ; 67.1,79.6)$ & $100(75.7 ; 68.3,83.2)$ \\
\hline No & $23(29.9 ; 20.2,41.5)$ & $55(27,6 ; 21.7,34.5)$ & $28(21.2 ; 14.8,29.4)$ \\
\hline Amount willing to pay $(n=238)(\$)^{*}$ & $(n=45 / 54)$ & $(n=110 / 143)$ & $(n=83 / 100)$ \\
\hline$<50$ & $14(31.0 ; 17.5,44.5)$ & $45(40.4 ; 30.9,49.3)$ & $30(36.1 ; 25.8,46.4)$ \\
\hline $50-100$ & $19(42.0 ; 27.6,56.4)$ & $30(27.2 ; 18.9,35.5)$ & $38(45.8 ; 35.1,56.5)$ \\
\hline $100-150$ & $6(13.0 ; 3.2,22.8)$ & $24(21.8 ; 14.1,29.5)$ & $8(9.6 ; 3.3,15.9)$ \\
\hline $150-200$ & $6(13.0 ; 3.2,22.8)$ & $4(3.6 ; 0.1,7.1)$ & $4(4.8 ; 0.2,9.4)$ \\
\hline $200-250$ & 0 & $7(6.4 ; 1.8,11.0)$ & $3(3.6 ;-0.4,7.6)$ \\
\hline
\end{tabular}

Note: *Based on those willing to attend a program who responded to the willingness to pay question in 2014 Canadian dollars.

Abbreviations: $\mathrm{OA}$, osteoarthritis; $\mathrm{Cl}$, confidence interval.

\section{Publish your work in this journal}

Patient Preference and Adherence is an international, peer-reviewed, open access journal that focuses on the growing importance of patient preference and adherence throughout the therapeutic continuum. Patient satisfaction, acceptability, quality of life, compliance, persistence and their role in developing new therapeutic modalities and compounds to optimize clinical outcomes for existing disease states are major areas of interest for the journal. This journal has been accepted for indexing on PubMed Central. The manuscript management system is completely online and includes a very quick and fair peer-review system, which is all easy to use. Visit http://www. dovepress.com/testimonials.php to read real quotes from published authors. 